\title{
Effect of Crystallinity on the Nonlinear Viscoelastic and Optical Properties of Undrawn and Drawn Poly(ethylene terephthalate) Films
}

\author{
Akira TANAKA, ${ }^{*}$ Hikoichi NAgAnO, Masayuki ShinOHARA, \\ and Shigeharu ONOGI** \\ Department of Polymer Chemistry, Kyoto University, Kyoto 606, Japan
}

(Received February 4, 1988)

\begin{abstract}
Simultaneous measurements of dynamic viscoelastic properties with dynamic birefringence in a nonlinear viscoelastic region were carried out for poly(ethylene terephthalate) films having different degrees of crystallinities. Two different types of nonlinear properties were found in undrawn films. One was associated with the slippage of amorphous chains in a low crystallinity region. Another was associated with the slippage of crystallites in the lamellae in a high crystallinity region. In an intermediate crystallinity region, on the other hand, very linear behavior was found. In the case of drawn films, two different nonlinearities were clearly observed. One found in a low crystallinity region was also associated with the slippage of amorphous chains. This nonlinearity might be essentially the same as that in a low crystallinity region of undrawn films. Another was associated with structural changes such as opening of cracks and cavitation in the amorphous region between spherulites or between crystallites, and was found in intermediate and high crystallinity regions. These two nonlinear features were also significantly different in the analysis with the ERSISC and non-linear Voigt element.

KEY WORDS Nonlinearity / Dynamic Viscoelasticity / Dynamic

Birefringence / Deformation Mechanisms / Poly(ethylene terephthalate) /

Nonlinear Voigt Element /
\end{abstract}

The nonlinear viscoelastic properties of crystalline polymers in solids is one of the most important properties of materials for practical use. Many works have thus been carried out, mainly with phenomenological or engineering approaches. However, there have been few works with an approach based on structural changes. In previous papers, ${ }^{1-5}$ the nonlinear viscoelastic properties of polyethylene films were studied from the view point of structural changes. The previous studies suggested that the nonlinear viscoelastic behavior of polyethylene films is associated with the plastic deformation such as slippage of crystallites in lamellae or void openings. Plastic deformation is caused by microscopic disruption of a spherulitic structure arising in the process of transformation from a spherulitic to a fiberous structure. Hence, it is expected that nonlinear features are dependent upon morphological states such as the degrees of crystallinity, and the size of spherulites, because it is likely that disruption features are dependent upon original morphological states.

It is well-known that poly(ethylene terephthalate) (PET) film is easily obtained in different states of order, such as different degrees of crystallinity and/or size of spherulites, and consequently, the filling volume of the spherulites in the films, by changing the crystal-

* To whom correspondence should be addressed.

** Present address: Matsue Technical College, Matsue 690, Japan. 
lization temperature and period of time of crystallization. $^{6-9}$

In this study, the nonlinear features of two morphologically different systems were investigated. One is undrawn PET films with different degrees of crystallinities. Another is drawn PET films in which spherulitic structures are disrupted to various extents.

The purpose of this study is to examine the effects of crystallinity on the Nonlinear viscoelastic and optical properties of undrawn and drawn PET films.

\section{EXPERIMENTAL}

\section{Samples and Their Characterization}

The PET films used in this study were obtained from Toyobo Co., Ltd. The asreceived PET films produced by being meltextruded and quenched were isotropic and almost amorphous. The density was $1.338 \mathrm{~g}$ $\mathrm{cm}^{-3}$ and the degree of crystallinity $c a .2 \mathrm{wt} \%$. To prepare films with different degrees of crystallinities $(2-50 \%)$ the as-received PET films were heated in an oven controlled at various temperatures between 100 and $200^{\circ} \mathrm{C}$. The heating period was $15 \mathrm{~min}$.

The density was measured at $30^{\circ} \mathrm{C}$ by the floating method, using an aqueous solution of $\mathrm{Ca}\left(\mathrm{NO}_{3}\right)_{2} 4 \mathrm{H}_{2} \mathrm{O}$. From the density, the degree of crystallinity was evaluated. For evaluation, the densities of the crystalline and amorphous regions were assumed to be 1.445 and $1.335 \mathrm{~g}$ $\mathrm{cm}^{-3}$, respectively. ${ }^{10}$ In Figure 1, the degree of crystallinity was plotted against crystallization temperature. In the same figure, spherulite size (diameter in micron) is plotted. Spherulite radius was evaluated from the $H_{\mathrm{v}}$-light scattering pattern using the method of Stein and Rhodes. ${ }^{11}$ As is clear from the figure, both the degree of crystallinity $X_{\mathrm{c}}(\mathrm{wt} \%)$ and diameter of the spherulites $\lambda(\mu \mathrm{m})$ suddenly increased between 100 and $120^{\circ} \mathrm{C}$, and then held constant between 120 and $140^{\circ} \mathrm{C}$ and increased again between 140 and $180^{\circ} \mathrm{C}$. This stepwise crystallization behavior has already been re-

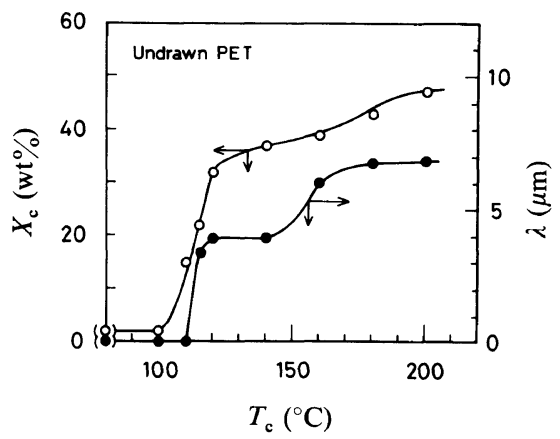

Figure 1. The variation of crystallinity $X_{\mathrm{c}}$ and spherulite size $\lambda$ (in diameter) with crystallization temperature $T_{\mathrm{c}}$ for PET films.

Table I. The density and degree of crystallinity for the undrawn and drawn PET films crystallized at different temperatures

\begin{tabular}{|c|c|c|c|c|}
\hline \multirow{2}{*}{$T_{\mathrm{c}} /{ }^{\circ} \mathrm{C}$} & \multicolumn{2}{|c|}{ Density $/ \mathrm{g} \mathrm{cm}^{-3}$} & \multicolumn{2}{|c|}{ Crystallinity $/ w t \%$} \\
\hline & Undrawn & Drawn & Undrawn & Drawn \\
\hline As-received & $1.338 \pm 0.001$ & $1.337 \pm 0.001$ & $2 \pm 1$ & $2 \pm 1$ \\
\hline 100 & $1.336 \pm 0.001$ & $1.337 \pm 0.001$ & $2 \pm 1$ & $1 \pm 1$ \\
\hline 110 & $1.351 \pm 0.001$ & $1.363 \pm 0.001$ & $15 \pm 1$ & $25 \pm 1$ \\
\hline 115 & $1.360 \pm 0.001$ & $1.367 \pm 0.001$ & $22 \pm 1$ & $29 \pm 1$ \\
\hline 120 & $1.371 \pm 0.001$ & $1.374 \pm 0.001$ & $32 \pm 1$ & $34 \pm 1$ \\
\hline 140 & $1.377 \pm 0.001$ & $1.376 \pm 0.001$ & $37 \pm 1$ & $36 \pm 1$ \\
\hline 160 & $1.380 \pm 0.001$ & - & $39 \pm 1$ & - \\
\hline 180 & $1.384 \pm 0.001$ & - & $43 \pm 1$ & - \\
\hline 200 & $1.389 \pm 0.001$ & - & $47 \pm 1$ & - \\
\hline
\end{tabular}

The crystallization time was $15 \mathrm{~min}$ and the drawing temperature, $96^{\circ} \mathrm{C}$. 
Nonlinear Viscoelastic and Optical Properties

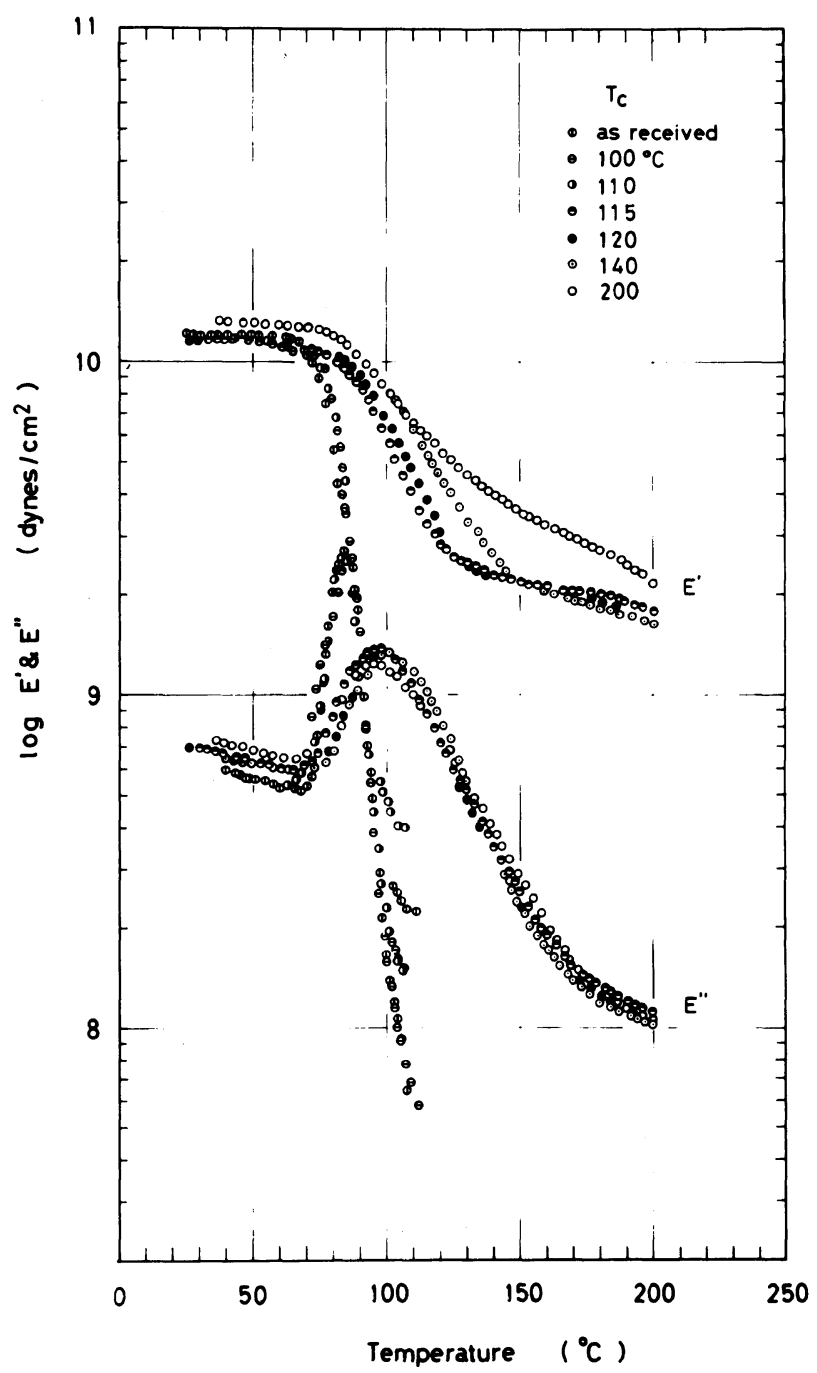

Figure 2. The variation of dynamic Young's modulus and loss modulus with temperature for undrawn PET films crystallized at different temperatures. The measuring frequency was $110 \mathrm{~Hz}$.

ported by Kilian, Halboth, and Jenckel, ${ }^{8}$ and Illers and Breuer. ${ }^{12}$

Films were drawn after being crystallized at desired temperatures. The draw ratio was 5 , and the drawing temperature was $96^{\circ} \mathrm{C}$. The change in the density with drawing was relatively small, as shown in Table I.

The dynamic viscoelastic properties were measured at $100 \mathrm{~Hz}$ by Rheovibron DDV-II ${ }_{c}$ (Toyo Baldwin Co.). The results are shown in Figures 2 and 3. As is clear from Figure 2, the storage moduli $E^{\prime}$ for the as-received films and films crystallized below $110^{\circ} \mathrm{C}$ dropped by two orders of magnitudes around $80^{\circ} \mathrm{C}\left(T_{\mathrm{g}}\right)$ and Young's loss modulus $E^{\prime \prime}$ had a maximum at about $85^{\circ} \mathrm{C}$. But $E^{\prime}$ for crystallized films above $115^{\circ} \mathrm{C}$ dropped only by one order of magnitude at most and $E^{\prime \prime}$ had a maximum at higher temperature (about $100^{\circ} \mathrm{C}$ ). These results were analogous to those already measured by some authors. ${ }^{12-19}$

On the whole, the temperature dependences 


\section{A. TANAKa et al.}

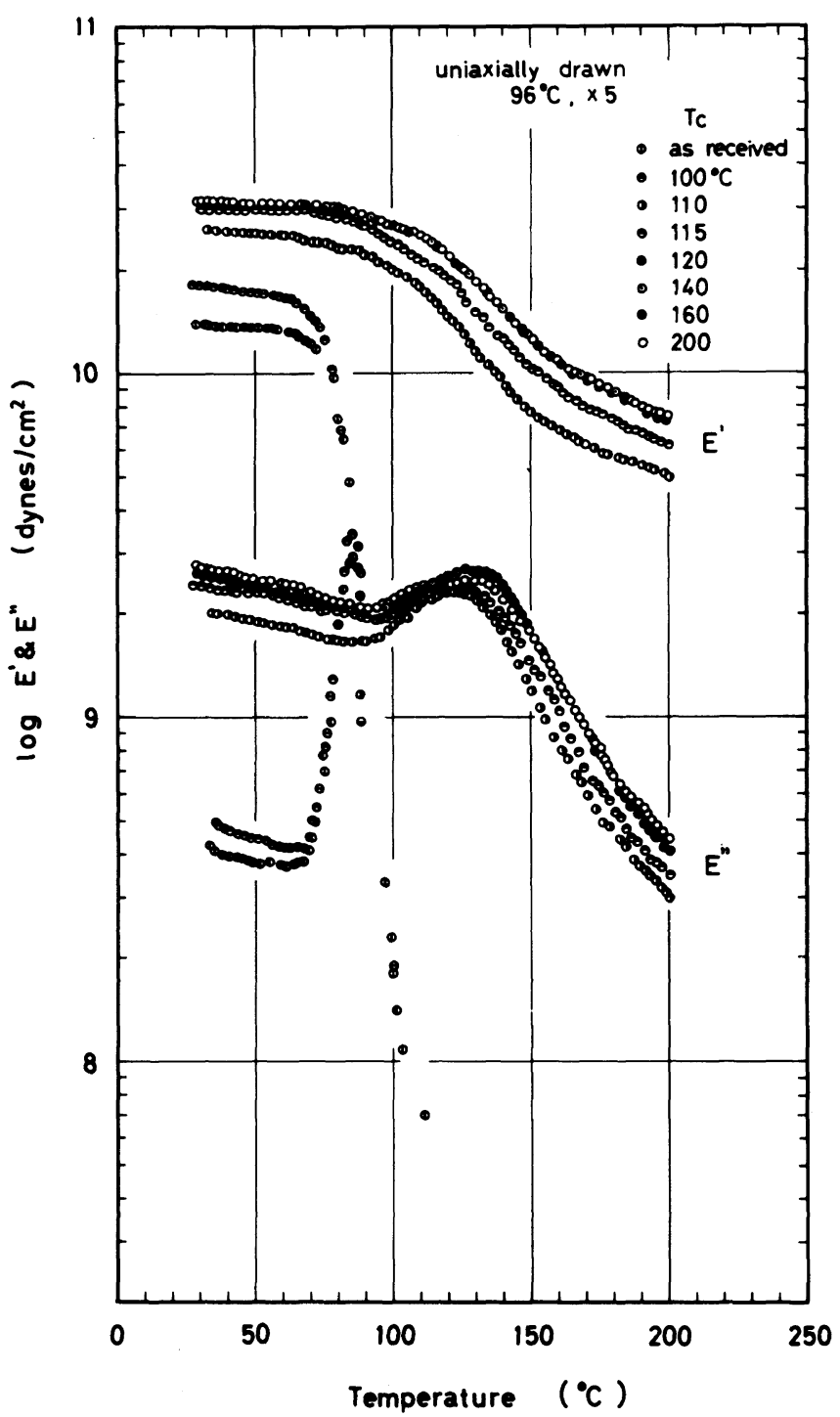

Figure 3. The variation of dynamic Young's modulus and loss modulus with temperature for drawn prepared by drawing the undrawn films precrystallized at different temperatures. The draw ratio was 5 , and drawing temperature was $96^{\circ} \mathrm{C}$. The measuring frequency was $110 \mathrm{~Hz}$.

of dynamic viscoelastic properties for drawn films were very similar to those for corresponding undrawn films, as shown in Figure 3. However, a few differences were seen. First, $E^{\prime}$ was a little higher, secondly, the drop in $E^{\prime}$ at $T_{\mathrm{g}}$ was smaller. Finally, the maximum of $E^{\prime \prime}$ shifted to higher temperature. It was suggested that the temperature at which amorphous chains are mobilized became higher with drawing.

Simultaneous Measurements of Dynamic Viscoelastic Properties and Dynamic Birefringenece in the Nonlinear Viscoelastic Region The simultaneous measurements of dynamic viscoelastic properties and dynamic birefringenece were carried out in the nonlinear viscoelastic region using the "Nonlinear Dynamic 
Viscoelastic Apparatus."1-3 The temperature was fixed at $96^{\circ} \mathrm{C}$ and the frequency at $0.05 \mathrm{~Hz}$. A static strain $\left(\gamma_{\mathrm{s}}\right)$ of $5 \%$ was first given to a specimen. After being allowed to relax for a long time, a dynamic strain $\left(\gamma_{\mathrm{d}}\right)$ ranging from 0.1 to $2.0 \%$ was superimposed on the static strain. The mechanical and optical parameters were determined after more than 20 cycles, by which time a stationary state was almost attained.

Only a brief description about mechanical and optical parameters used in the present paper will be described, as the details of parameters have already been described. ${ }^{1-3}$ $\left|E_{1}^{*}\right|$ and $\left|K_{1}^{*}\right|$ are the absolute values of complex Young's modulus and complex strain-optical coefficients (s.o.c., i.e., birefringence/strain), and $\tan \delta_{1}$ and $\tan \alpha_{1}$ are the tangent losses of the stress and s.o.c with respect to the dynamic strain. $\delta_{1}$ indicates a phase lead and $\alpha_{1}$ a phase lag, respectively. A subscript 1 represents the fundamental component in the Fourier expansion. $P_{\sigma}$ and $P_{\Delta}$ are the nonlinear mechanical and optical parameters, respectively. The nonlinear parameters are given by the total deviation of the stress (or s.o.c.) from the corresponding fundamental components per one cycle of the dynamic strain. The nonlinear parameters represent the degrees of mechanical and optical nonlinearities.

\section{RESULTS AND DISCUSSION}

\section{Nonlinear Viscoelasticity of Undrawn Films}

Figure 4 shows the variation of mechanical parameters with the dynamic strain. The figure includes the results for nine undrawn films crystallized at diffrent temperatures. The degree of crystallinity $X_{\mathrm{c}}$ as well as the crystallization temperature $T_{\mathrm{c}}$ are indicated at the top of the figures. As is clear from all the figures, $\left|E_{1}^{*}\right|$ 's decreased with increasing $\gamma_{\mathrm{d}}$, irrespcetive of $T_{\mathrm{c}}$. The higher the $T_{\mathrm{c}}$, the decrease became less. The $\left|E_{1}^{*}\right|$, as a whole, increased with increasing $T_{\mathrm{c}}$ and tended to level off at high $T_{\mathrm{c}}$ 's. The values of $\tan \delta_{1}$ were around 0.2 over the entire $T_{\mathrm{c}}$ and $\gamma_{\mathrm{d}}$ region. $P_{\sigma}$ 's for the films crystallized at low temperatures were high at low $\gamma_{d}$ and decreased with increasing $\gamma_{\mathrm{d}}$. On the other hand, for the films crystallized at high temperatures, they were low at low $\gamma_{d}$, and increased with increasing $\gamma_{d}$. For films crystallized at intermediate temperatures, they were very low in the whole $\gamma_{d}$ region.

Figure 5 shows the variation of optical parameters with dynamic strain. The figure includes the results for nine undrawn films crystallized at different temperatures. The $\left|K_{1}^{*}\right|$ showed little dependence on the dynamic strain. But the values, as a whole, increased toward an equilibrium value with increasing with $T_{\mathrm{c}}$. The sign of $-\tan \alpha_{1}$ for the films crystallized at low temperatures was negative for almost all $\gamma_{d}$ 's. For the films crystallized at intermediate temperature, it varied from negative to positive with increasing $\gamma_{d}$. For the films crystallized at high temperatures, it showed a constant and positive value for all $\gamma_{d}$ 's. The variations of $P_{\Delta}$ with $\gamma_{d}$ were various among different films. However, the variation with $T_{\mathrm{c}}$ showed a similar tendency to that of $P_{\sigma}$. That is, the $P_{\Delta}$ of the films crystallized at temperatures lower than $115^{\circ} \mathrm{C}$ and higher than $160^{\circ} \mathrm{C}$ were high, and the $P_{\Delta}$ 's of the films crystallized at intermediate temperature were low.

As is suggested from the $\gamma_{d}$ dependence curves, the mechanical and optical parameters can be classified into the following three groups, depending upon the $T_{\mathrm{c}}$ :

(I) $T_{\mathrm{c}} \leq 100^{\circ} \mathrm{C}$

(II) $110^{\circ} \mathrm{C} \leq T_{\mathrm{c}}<120^{\circ} \mathrm{C}$

(III) $T_{\mathrm{c}} \geq 120^{\circ} \mathrm{C}$

Lissajous figures of stress-strain and birefringence-strain also showed different features in the different groups as schematically shown in Figure 6. In group I, the Lissajous figures of birefringence-strain showed a parallelogramlike loop. In group II, Lissajous figures of both stress-strain and birefringence-strain showed a 

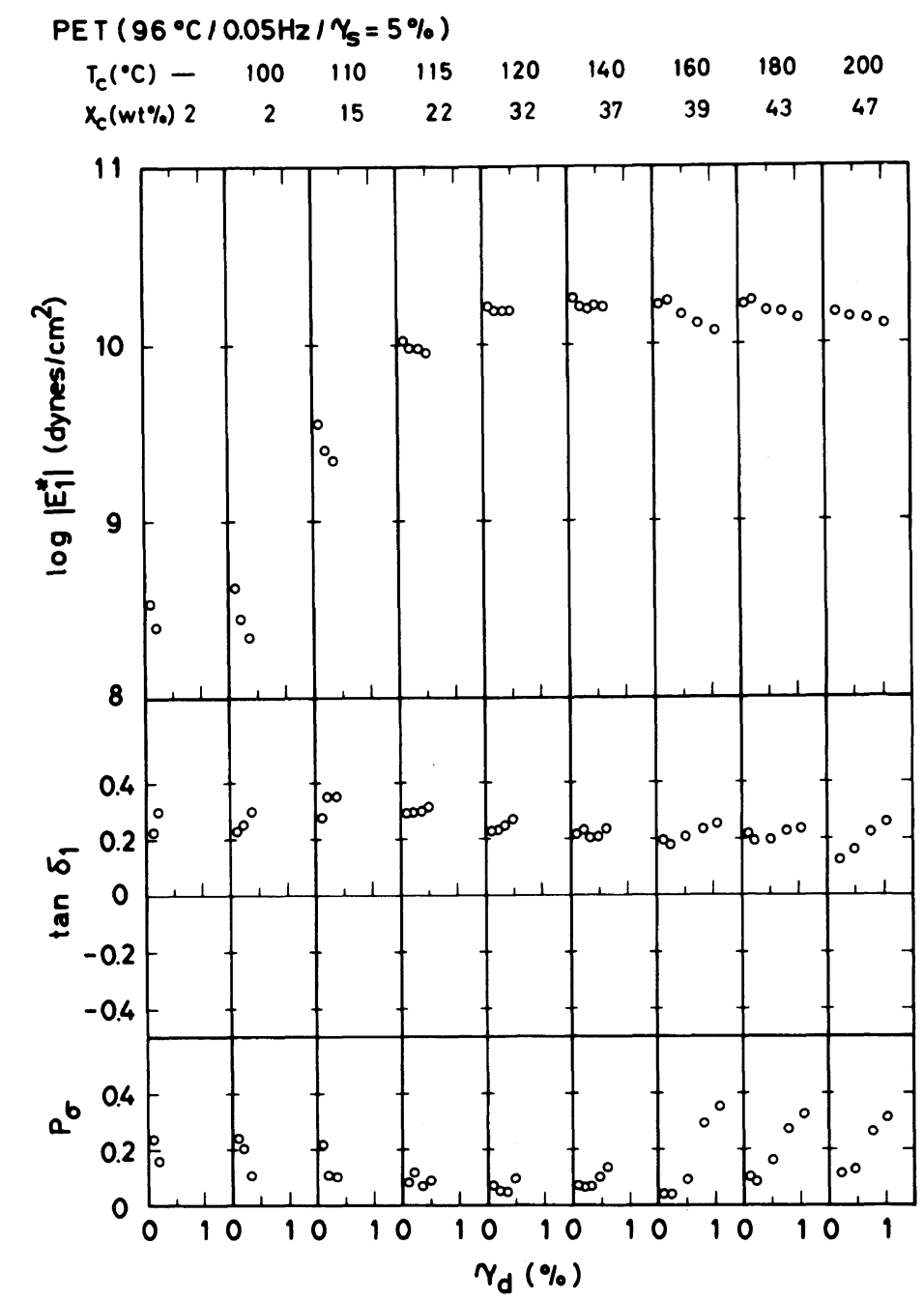

Figure 4. The variation of $\left|E_{1}^{*}\right|, \tan \delta_{1}$, and $P_{\sigma}$ with dynamic strain $\gamma_{\mathrm{d}}$. The figure includes the results of nine different undrawn PET films with different degrees of crystallinities. The static strain was $5 \%$. The measuring temperature and frequency was $96^{\circ} \mathrm{C}$ and $0.05 \mathrm{~Hz}$, respectively.

very smooth ellipse. In group III, Lissajous figures of both stress-strain and birefringencestrain showed a sharp and bowed ellipse at the maximum strain.

The high values of $\left|E_{1}^{*}\right|$ may involve the deformation of crystalline phase such as the affine deformation of spherulites and the orientation of the crystallites in lamellae. The negative value of $-\tan \alpha$ may indicate that deformation mechanisms which cause an increase in birefringence are dominant. The de- formation mechanism is supposed to be the orientation of amorphous chains in the stretching direction. On the other hand, the positive value of $-\tan \alpha$ may suggest that there exist at least two different types of deformation mechanisms which contribute to the birefringence in different manners. One is the orientation of crystallites or amorphous chains in the stretching direction, which causes an increase in birefringence with drawing. Another is the affine deformation of the spherulitic 


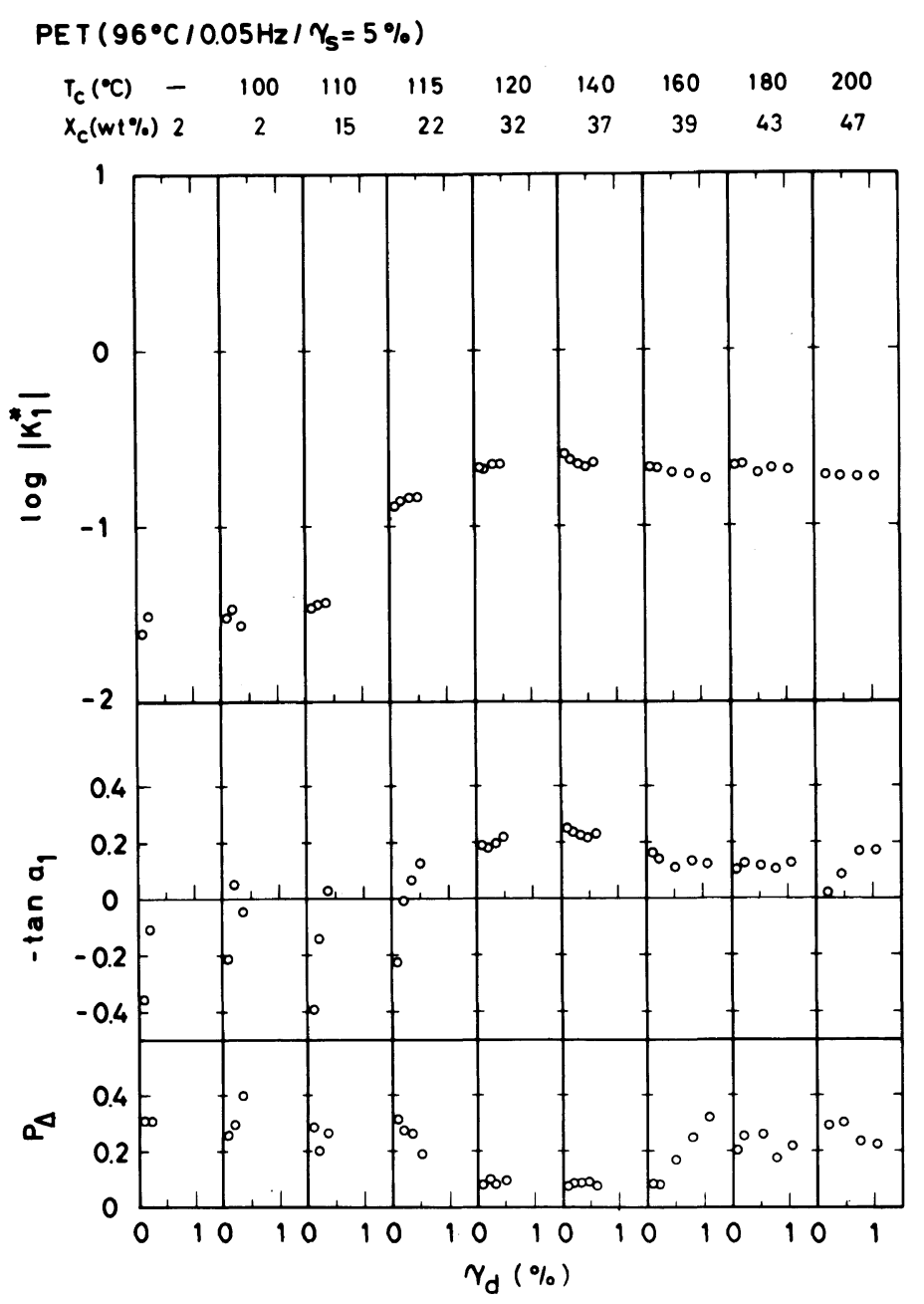

Figure 5. The variation of $\left|K_{1}^{*}\right|,-\tan \alpha_{1}$, and $P_{\Delta}$ with dynamic strain $\gamma_{\mathrm{d}}$. The figure includes the results of nine different undrawn PET films with different degrees of crystallinities. The static strain was $5 \%$. The measuring temperature and frequency was $96^{\circ} \mathrm{C}$ and $0.05 \mathrm{~Hz}$, respectively.

structure, which causes a decrease in birefringence with drawing. Thus, the nonlinear feature in each of the groups is considered as follows.

In group I, the crystalline phase dispersed in the amorphous matrix is very small in amount. Hence, there are very few or no crosslinking points. Small amounts of crosslinking points may cause a slippage as well as a reduction in orientation of amorphous chains. It is suggested that the nonlinear responses of the mechanical and optical quantities may be attributable to the slippage of amorphous chains, more or less.

In group III, on the other hand, the spherulitic structures fill the volume of the film specimen. So, slippage of amorphous chains hardly occurs. But microscopic disruption of spherulites may arise, even though a sample specimen is drawn uniformly in a macroscopic sense. The disruption of spherulites must accompany the slippage of crystallites, which causes a nonlinear response of the mechanical and optical quantities. This nonlinear property 


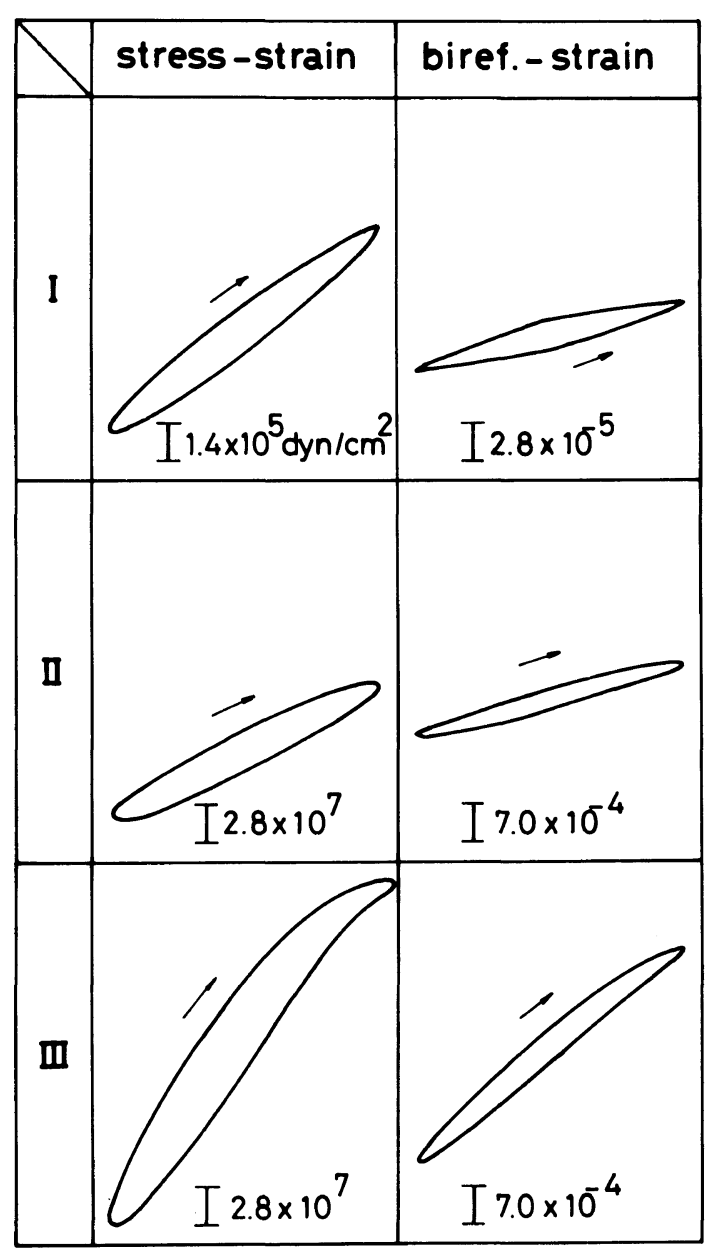

Figure 6. Schematical representation of typical Lissajous figures of stress $v s$. strain (left) and birefringence vs. strain (right) for undrawn PET films in three different regions.

was quite analogous to that found in polyethylene films. ${ }^{1-5}$

In group II, neither slippage of amorphous chains nor slippage of crystallites occurs in a specimen, and only linear responses such as the orientation of amorphous chains and the affine deformation of spherulite occur. This is probably attributable to the degree of crystallinity and crystal size. In this situation, the crystallites play a role of crosslinking, but they do not deform themselves. The amorphous chains orient linearly with strain but do not slip past one another. Such deformation mechanisms are supposed to make the nonlinear parameters small.

\section{Nonlinear Viscoelastic Properties of Drawn Films}

As reported elsewhere, ${ }^{20}$ the drawn films had three different kinds of morphologies, depending upon the degree of crystallinity in the undrawn state. The drawn films precrystallized below $100^{\circ} \mathrm{C}$ exhibited a small birefringence and no light scattering. This may indicate that there are very few or no crystallites and that there is little orientation of the amorphous chains with drawing. The drawn films precrystallized between 110 and $115^{\circ} \mathrm{C}$ gave a four leaf clover pattern in the $H_{\mathrm{v}}$-light scattering picture and a relatively high birefringence. This observation suggests that many small size spherulites which remain undeformed are dispersed within the matrix consisting of oriented amorphous chains. Such a feature was ascertained from optical microscopic and scanning electron microscopic observations. ${ }^{20}$ The drawn films precrystallized above $120^{\circ} \mathrm{C}$ gave high birefringence and an extended four leaf clover pattern in the $H_{\mathrm{v}}$-light scattering picture, suggesting that both amorphous chains and crystallites oreint considerably in the drawing direction.

The variation of mechanical and optical properties with the dynamic amplitude of strain for drawn PET films is shown in Figures 7 and 8. As is evident from the figures, their variations can be classified into the following two groups, (although the drawn films are classified into three groups from a morphological point of view).

$$
\begin{aligned}
& \text { (IV) } T_{\mathrm{c}} \leq 100^{\circ} \mathrm{C} \\
& \text { (V) } T_{\mathrm{c}} \geq 110^{\circ} \mathrm{C}
\end{aligned}
$$

In group IV, the mechanical and optical properties were essentially the same as those (group I) for undrawn films. That is, $\left|E_{1}^{*}\right|$ and $\left|K_{1}^{*}\right|$ had considerably low values, and $\tan \delta_{1}$ 

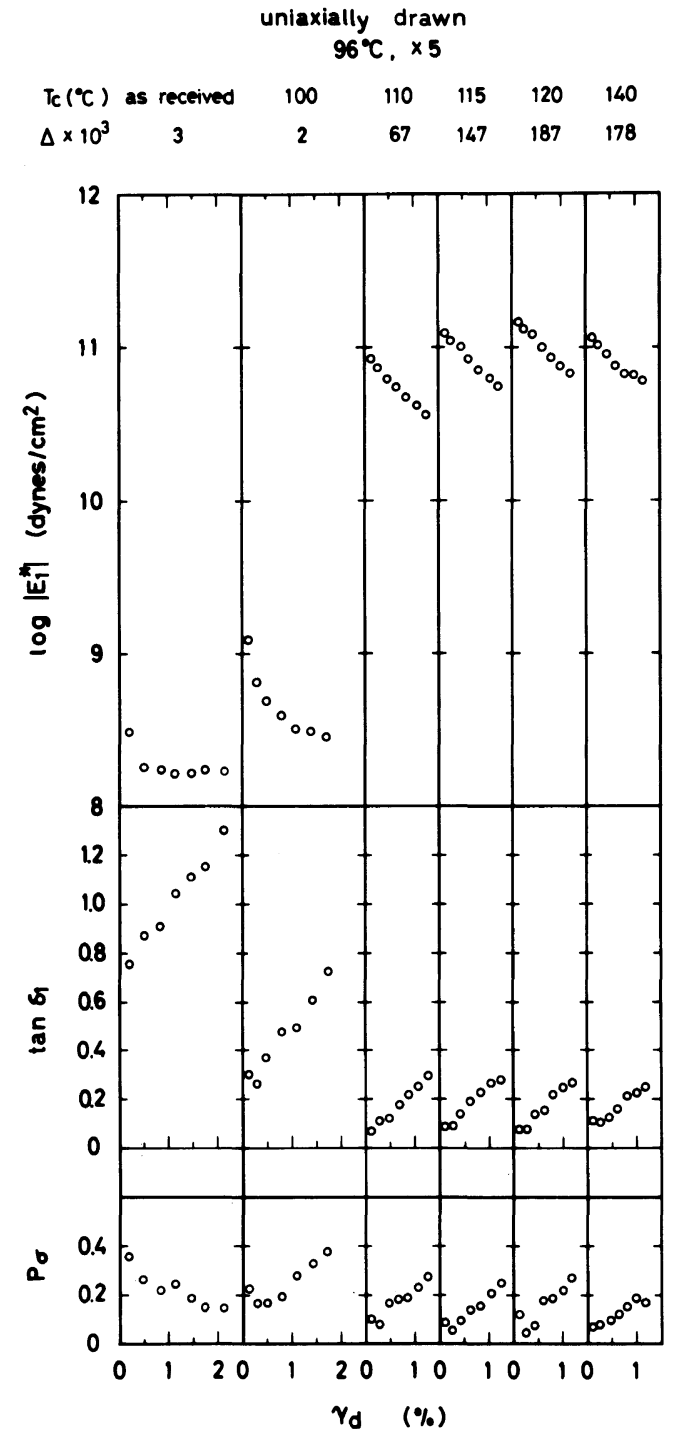

Figure 7. The variation of $\left|E_{1}^{*}\right|, \tan \delta_{1}$, and $P_{\sigma}$ with dynamic strain $\gamma_{d}$ for drawn PET films in which the precrystallization temperatures at an undrawn state are different. The draw ratio was 5 , and the drawing temperature was $96^{\circ} \mathrm{C}$. The static strain was $5 \%$. The measuring temperature and frequency were $96^{\circ} \mathrm{C}$ and $0.05 \mathrm{~Hz}$, respectively.

and $-\tan \alpha_{1}$ had high values. $P_{\sigma}$ was high. However, they were a little different from those (group I) for undrawn films. $-\tan \alpha_{1}$ of the drawn films was positive. $P_{\Delta}$ of the drawn films was smaller than that of undrawn film.
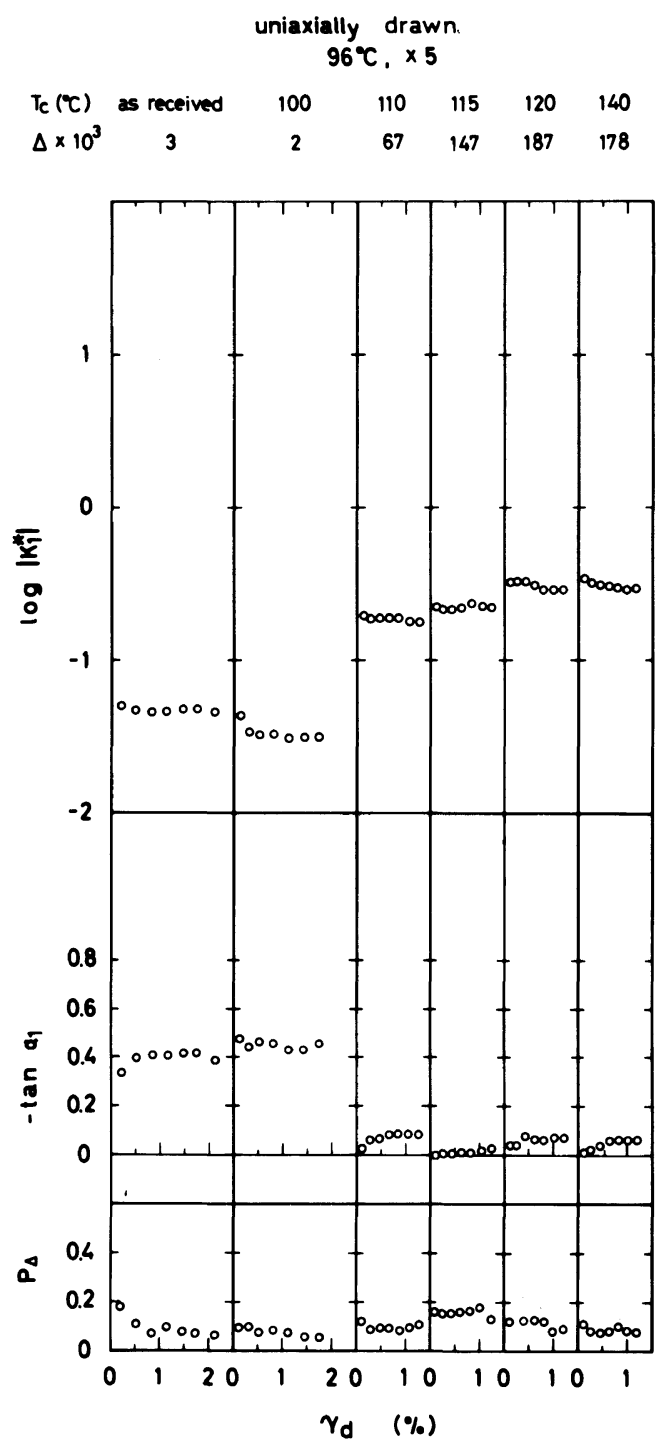

Figure 8. The variation of $\left|K_{1}^{*}\right|,-\tan \alpha_{1}$, and $P_{\Delta}$ with dynamic strain $\gamma_{d}$ for drawn PET films in which the precrystallization temperatures at an undrawn state are different. The draw ratio was 5 , and drawing temperature was $96^{\circ} \mathrm{C}$. The static strain was $5 \%$. The measuring temperature and frequency were $96^{\circ} \mathrm{C}$ and $0.05 \mathrm{~Hz}$, respectively.

Supposedly, the differences may indicate that the slippage of amorphous chains in the drawn films during an oscillatory deformation is less than that for undrawn films and that the orientation of amorphous chains for drawn 


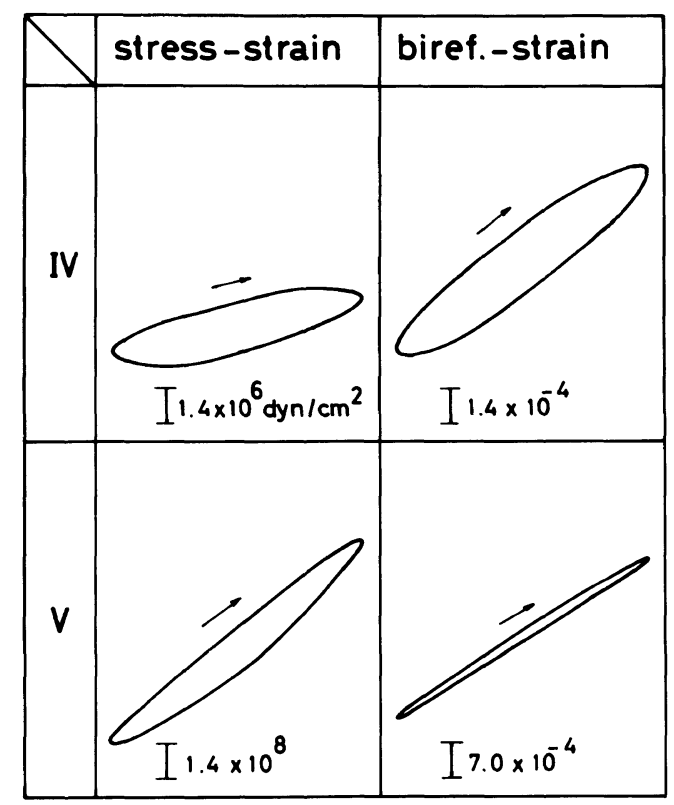

Figure 9. Schematical representation of typical Lissajous figures of stress $v s$. strain (left) and birefringence vs. strain (right) for drawn PET films in two different regions.

films during an oscillatory deformation is higher than that for undrawn films.

In group $\mathrm{V},-\tan \alpha_{1}$ was near zero, and $P_{\Delta}$ was relatively small. This indicates that orientations of both amorphous chains and crystallites respond elastically without plastic deformation such as slippage of amorphous chains and crystallites. However, $\tan \delta_{1}$ and $P_{\sigma}$ increase with increasing $\gamma_{\mathrm{d}}$. In other words, mechanical parameters are nonlinear with respect to strain amplitude, but they are linear with respect to time.

The Lissajous figure of stress-strain in group $\mathrm{V}$ exhibited a unique feature, as schematically shown in Figure 9. That is, the stress distorted in an upward direction at a high strain. Such a distortion was not observed for the undrawn films. This nonlinear feature cannot be understood in terms of deformation mechanisms such as the slippage of amorphous chains and crystallites. Therefore, other mechanisms must be sought as an origin of nonlinear visco-

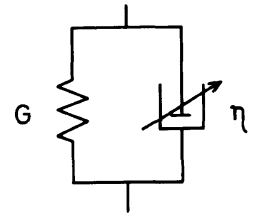

Figure 10. The nonlinear Voigt element.

elasticity. They may be the mechanisms such as opening of cracks and creation of voids under stress, whose details will be discussed later.

We have previously pointed out that there are not any essential differences in the nonlinear mechanical and optical properties among drawn films of group $\mathrm{V}$ in spite of the fact that there are different types of morphologies. However, it should be noted that the appearance of a different type of distortion was seen in the Lissajous figure for the film with $T_{\mathrm{c}}=140^{\circ} \mathrm{C}$. The stress deviates in a downward direction at high strain. This type of distortion was also seen for undrawn films (group III). The distortion is supposed to be caused by the slippage of crystallites. Thus, a third nonlinearity may be found in drawn films, when one measures at different time scales or uses films crystallized at higher temperatures.

\section{The Analysis by Nonlinear Voigt Elements}

The parameters $P_{\sigma}$ and $P_{\Delta}$, as mentioned above, represent the degree of mechanical and optical nonlinearity which are evaluated by averaging over a cycle of the dynamic strain. However, in order to get a more detailed relationship between the nonlinear viscoelasticity and structural changes, it is desirable to analyze the skewed Lissajous of stress-strain and birefringence-strain quantitatively. For this purpose, a nonlinear Voigt element is newly introduced, as shown in Figure 10. In the nonlinear Voigt element, it is assumed that the viscosity of dashpot $\eta$ varies with a periodic strain but the modulus of spring $G$ holds constant against a periodic strain. 
$G$ and $\omega \eta(\theta)(\theta$, phase angle of strain, $\omega$, angular frequency) were evaluated as follows. First, in a given Lissajous figure between stress and strain, $G$ was calculated by using experimental values of $\sigma(90)$ and $\sigma(270)$ in eq 1 (see Appendix 1)

$$
G=(\sigma(90)-\sigma(270)) / 2 \gamma_{\mathrm{d}}
$$

where $\sigma(90)$ and $\sigma(270)$ are the stresses at the phase angle of strain of $90^{\circ}$ and $270^{\circ}$, respectively. Secondly, $\omega \eta(\theta)$ was determined by fitting the data to the Voigt element. $\omega \eta(\theta)$ was represented by fraction. One fraction was defined by $(\omega \eta)_{\text {ave }} / 20$. Here, $(\omega \eta)_{\text {ave }}$ is $G \tan \delta_{1}$, where $\tan \delta_{1}$ is given by Fourier analysis. When the Lissajous figure is an ideal ellipse without any skew, the value of $\omega \eta$ becomes 20 over all the phase angle, because $\omega \eta$ is constant $\left((\omega \eta)_{\text {ave }}\right)$ independent of the phase angle $\theta$.

This analysis was also applied to birefringence-strain data in a similar fashion. In this analysis, the total birefringence $\Delta$ was assumed to be the sum of the birefringences of spring and dashpot in the nonlinear Voigt element; that is,

$$
\Delta=\Delta_{\mathrm{s}}+\Delta_{\mathrm{d}}
$$

Furthermore, the following relations were assumed:

$$
\Delta_{\mathrm{s}}=C_{\mathrm{s}} \sigma_{\mathrm{s}}
$$

and

$$
\Delta_{\mathrm{d}}=C_{\mathrm{d}} \sigma_{\mathrm{d}}
$$

where $C_{\mathrm{s}}$ and $C_{\mathrm{d}}$ are the stress-optical coefficients, $\Delta_{\mathrm{s}}$ and $\Delta_{\mathrm{d}}$ the birefringences, $\sigma_{\mathrm{s}}$ and $\sigma_{\mathrm{d}}$ the stresses where the subscripts $s$ and $d$ represent the spring and dashpot, respectively.

Using the model, $C_{\mathrm{s}} G$ and $C_{\mathrm{d}} \omega \eta(\theta)$ were calculated by means of the same procedure as for the mechanical one described above. Then, $C_{\mathrm{d}}(\theta)$ and $C_{\mathrm{s}}$ were evaluated from the ratio of optical variables $\left(C_{\mathrm{d}} \omega \eta(\theta)\right.$ and $\left.C_{\mathrm{s}} G\right)$ to mechanical variables $(\omega \eta(\theta)$ and $G)$, respectively. Here, we have to pay attention to the following point. That is, $C_{\mathrm{d}}$ and $C_{\mathrm{s}}$ include the contribution of the structural change such as a slippage of crystallites, which does not contribute to birefringence because the parameters are influenced also by the change in stress.

Figures 11 and 12 show the results of the analysis applied to data at a fixed dynamic strain for undrawn and drawn PET films, respectively. The dynamic strain was $0.5 \%$ for undrawn films and $1.0 \%$ for drawn films. For some cases in which data could not be obtained at $0.5 \%$, the dynamic strain was taken to be $0.2 \%$.

The results for undrawn films can be classified into the same three groups, as done previously (see Figure 11). The characteristic features were as follows.

First, the variation of $\omega \eta$ with $\theta$ is large in groups I and HI, and small in group II. This indicates that the Lissajous figure in group II is smoother than those in groups I and III, in other words, that the degree of nonlinearity in group II is lower those in groups I and III. Secondly, $\omega \eta$ shows a maximum at $\theta=0^{\circ}$ and a minimum at $\theta=180^{\circ}$, regardless of the group. In grroup III, a shoulder is seen around $230^{\circ}$ of $\theta$. Thirdly, and most surprisingly, the $C_{\mathrm{d}}$ 's vary quite smoothly with $\theta$ in spite of the fact that $C_{\mathrm{d}} \omega \eta$ 's vary in a complicated manner. The variation of $C_{\mathrm{d}}$ with $\theta$ is well characterized according to the groups. That is, the $C_{\mathrm{d}}$ in group I shows a maximum at $\theta=0^{\circ}$, that in group II at $\tau=90^{\circ}$, and that in group III at $\theta=$ $180^{\circ}$.

The value of unit fraction is indicated on the right hand side of Figure 11a and $11 \mathrm{~b}$, and the stress optical coefficient of spring in the nonlinear Voigt element $\left(C_{\mathrm{s}}\right)$ is indicated by an arrow on the left hand side and also by a figure on the right hand side of Figure 11c. The negative value of unit fraction in $C_{\mathrm{d}} \omega \eta$ comes from counter-clockwise rotation in the Lissajous figure of birefringence and strain. This indicates the phase lead of birefringence with respect to the strain.

These analyses were also done at different dynamic strains, though the results are not 


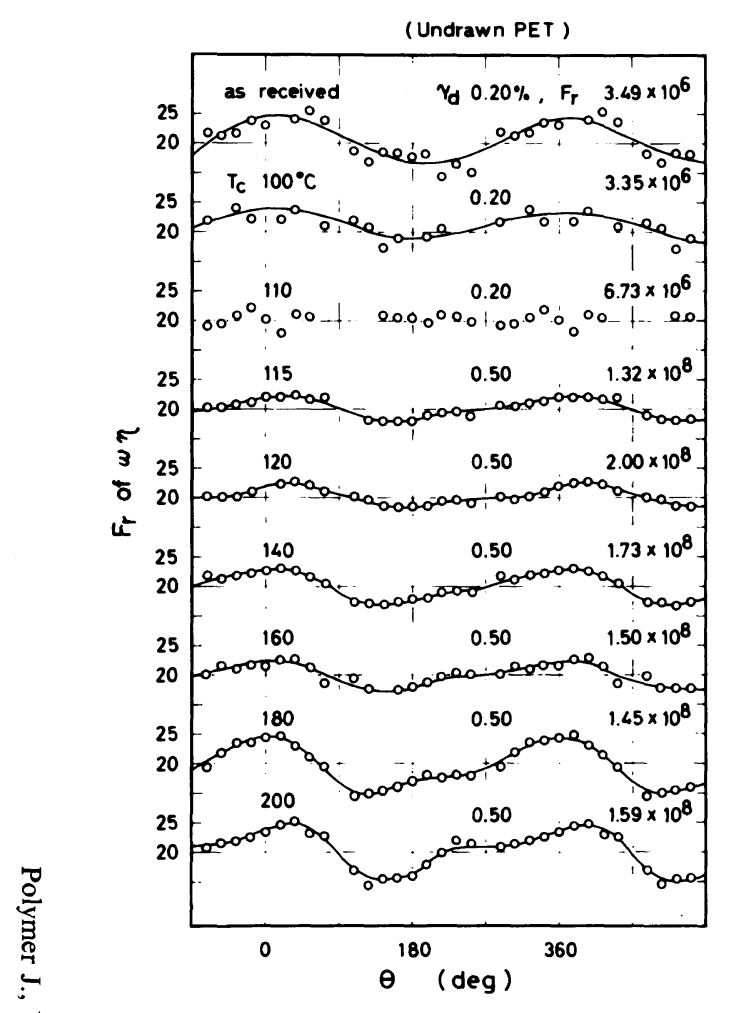

(a)

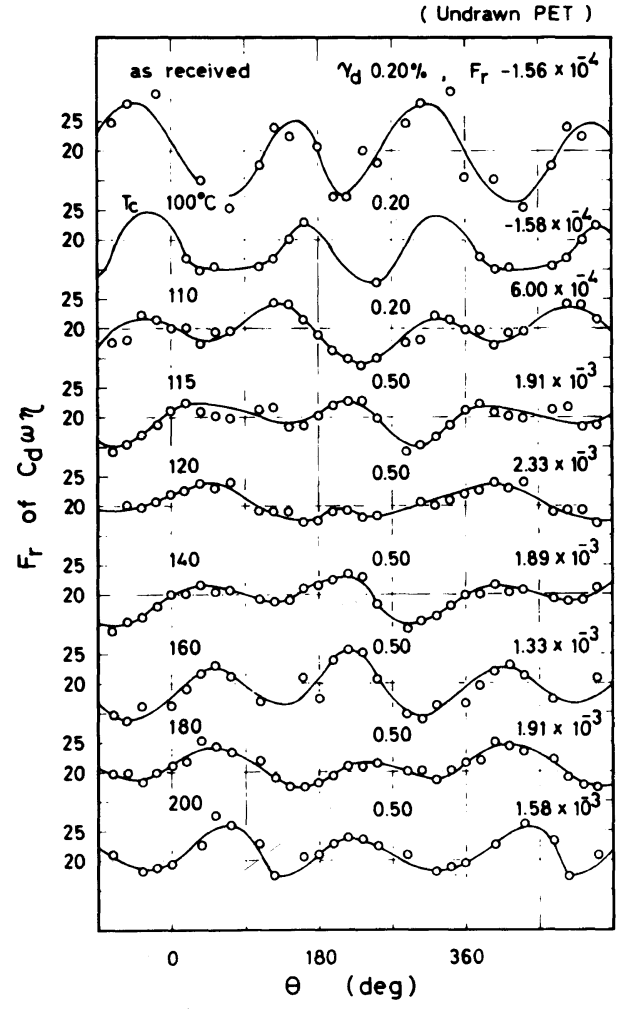

(b)

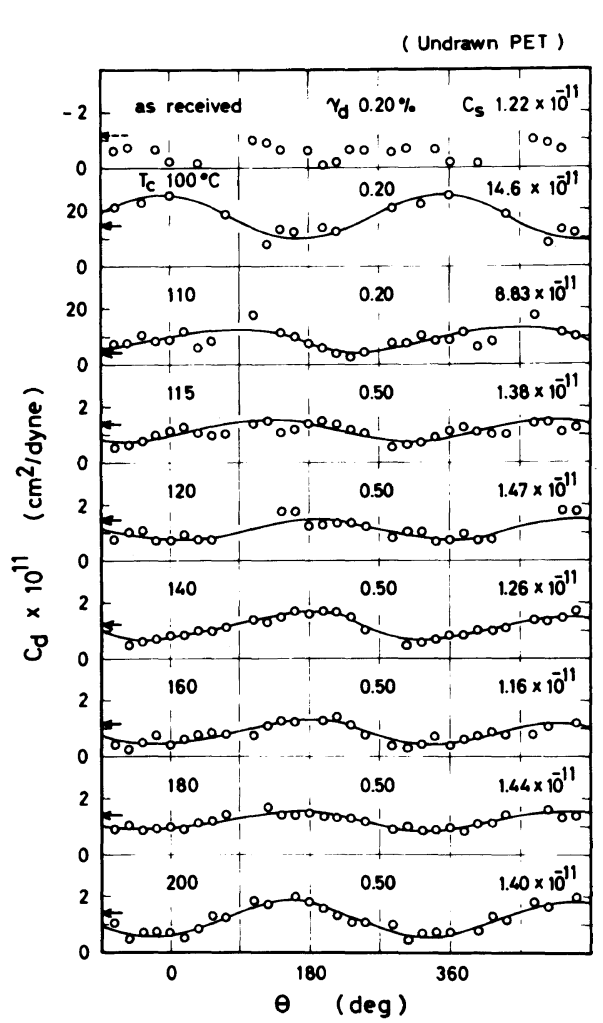

(c)

Figure 11. The variation of (a) fraction of $\omega \eta$, (b) fraction of $C_{\mathrm{d}} \omega \eta$, and (c) $C_{\mathrm{d}}$ with the phase angle $\theta$ at a fixed $\gamma_{\mathrm{d}}$ for undrawn PET films. 


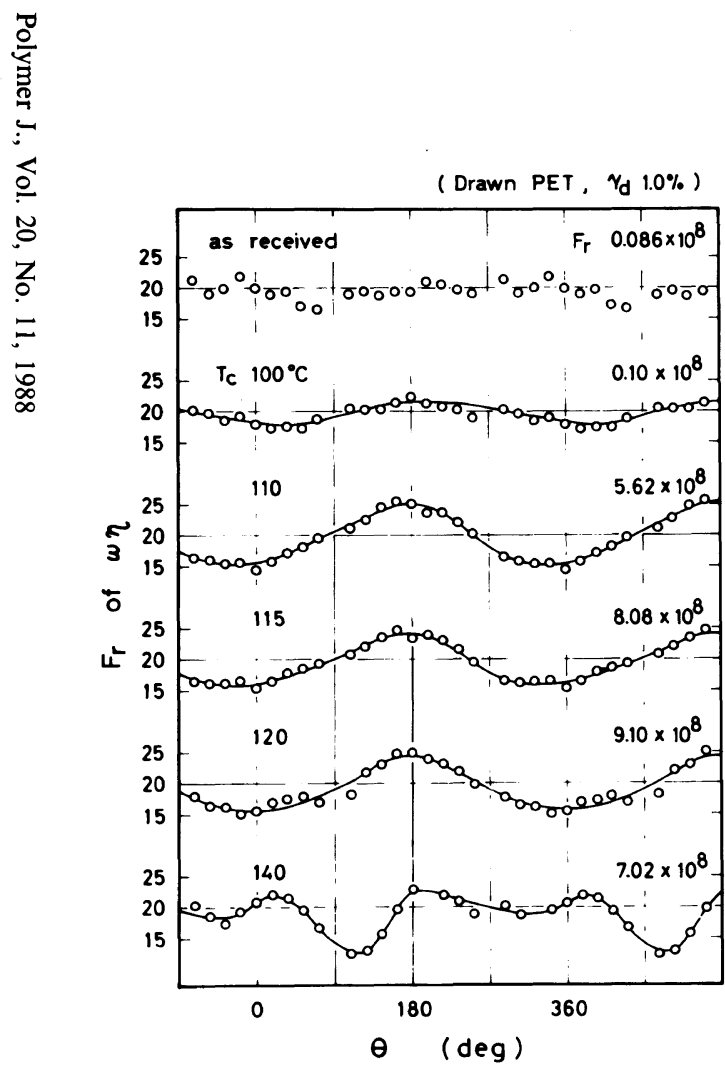

(a)

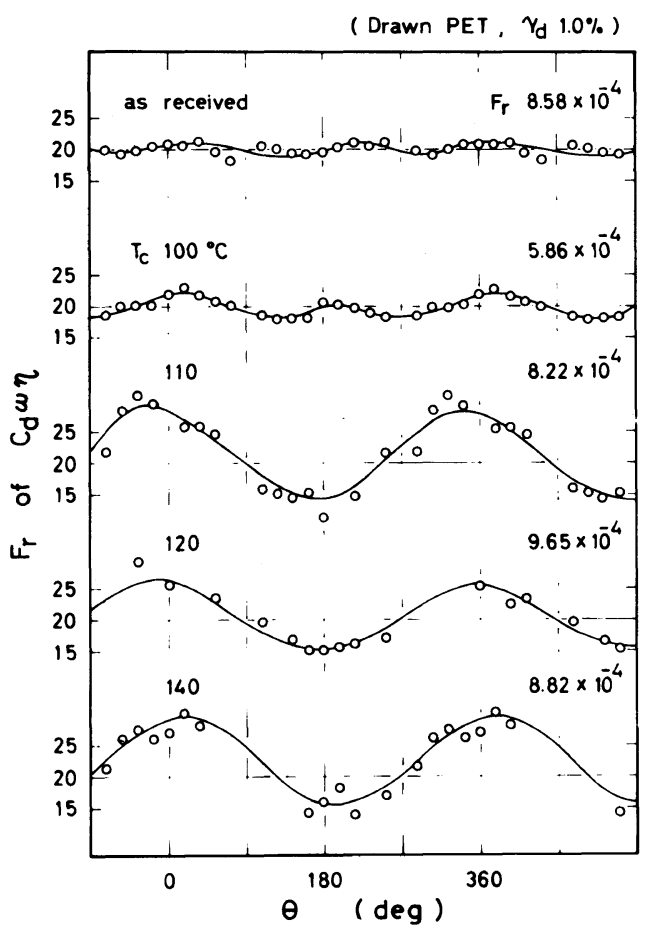

(b)

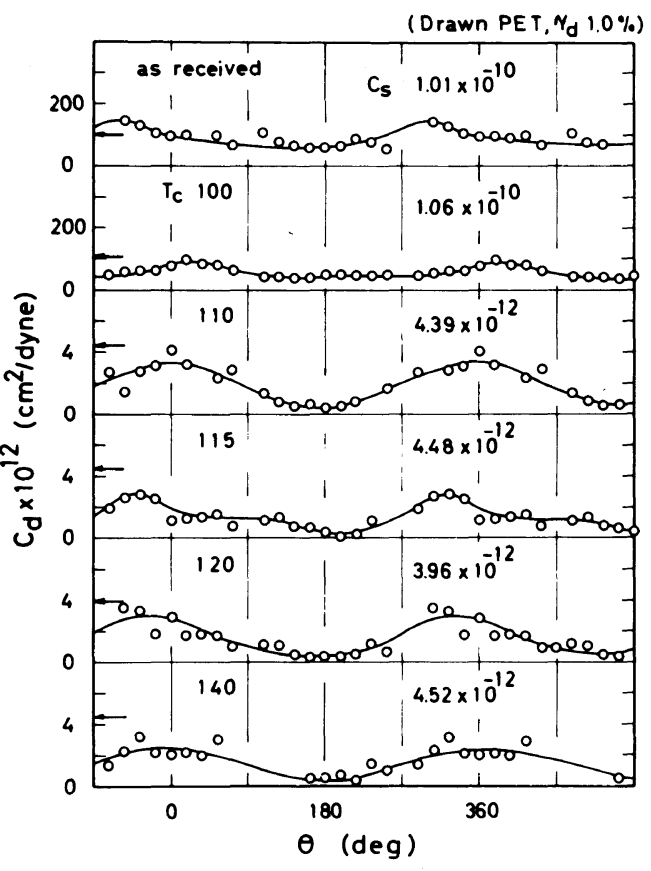

(c)

Figure 12. The variation of (a) fraction of $\omega \eta$, (b) fraction of $C_{\mathrm{d}} \omega \eta$, and (c) $C_{\mathrm{d}}$ with the phase angle $\theta$ at a fixed $\gamma_{\mathrm{d}}$ for drawn PET films. 
given here as figures. Their $\gamma_{d}$ dependence was also different from group to group. First, the variation of $\omega \eta$ in group I became smaller with increasing $\gamma_{\mathrm{d}}$, while those in groups II and III became bigger. But the $\gamma_{d}$ dependence in group II was quite small and the values themselves were quite low. Quite naturally, this feature coincided with the $\gamma_{\mathrm{d}}$ dependence of $P_{\sigma}$. Secondly, in group $I$, the fraction of $\omega \eta$ indicated a relatively smooth sinusoidal variation against $\theta$ even at high $\gamma_{\mathrm{d}}$. On the other hand, in group III, a shoulder around $230^{\circ}$ of $\theta$ (in a compression stage) became bigger with increasing $\gamma_{\mathrm{d}}$. However, such a shoulder was not seen in the variation of $C_{\mathrm{d}}$ with $\theta$. It may be suggested that at least two deformation mechanisms contribute to the force (deformation) in compression, but that one of them does not contribute to the birefringence. It is speculated that the mechanism must be slippage of crystallites in lamella, which is caused by microscopic disruption of the spherulitic structure.

In the case of drawn films, the variations of $\omega \eta, C_{\mathrm{d}} \omega \eta$, and $C_{\mathrm{d}}$ with $\theta$ can also be classified into two groups, as done for the nonlinear mechanical and optical parameters (see Figure 12). The value of $\omega \eta$ is at a maximum at $\theta=$ $180^{\circ}$ and minimum at $\theta=0^{\circ}$ for both groups IV and V. However, the variation in $\omega \eta$ is larger in group IV than in group V. Also the variation of $\omega \dot{\eta}$ for the drawn films precrystallized at $140^{\circ} \mathrm{C}$ is exceptionally complicated, as indicated by the shoulder around $\theta=0^{\circ}$ and a drop around $90^{\circ}$. On the other hand, both $C_{\mathrm{d}} \omega \eta$ and $C_{\mathrm{d}}$ take a maximum at $\theta=0^{\circ}$ and minimum at $\theta=180^{\circ}$ for both groups IV and $\mathrm{V}$. The $\gamma_{\mathrm{d}}$ dependences of these plots, in the case of drawn films, were very small.

\section{Evaluation of ERSICS by Using the Nonlinear Voigt Element}

Prevorsek, Kwon, and Sharma introduced the variable which is called (ERSICS). ${ }^{21,22}$ ERSISC is defined as the difference in energy loss in extension and in contraction as follows:

$$
\Delta \xi_{\mathrm{ext}}=\xi / 2-\xi_{\mathrm{ext}}
$$

where $\xi$ and $\xi_{\text {ext }}$ are the energy losses in a whole cycle and in extension, respectively. The energy losses are defined by eq 6 and 7 .

$$
\xi=\pi \bar{E} \gamma_{\mathrm{d}}^{2} \sin \bar{\delta}
$$

and

$$
\xi_{\text {ext }}=(1 / 2) \pi \bar{E}_{\text {ext }} \gamma_{d}^{2} \sin \bar{\delta}_{\text {ext }}
$$

where $\bar{E}, \bar{E}_{\text {ext }}$, and $\bar{\delta}_{\text {ext }}$ are averaged values of dynamic modulus and phase difference in a whole cycle and those in extension. These values, in this study, can be estimated by the dynamic moduli and loss tangents as a function of $\theta$ which are obtained from analysis by the nonlinear Voigt element.

Prevorsek et al. mentioned that the determination of ERSISC is a very useful tool in the interpretation of fracture and fatigue of polymer materials. ${ }^{21,22}$ Energy released in extension and absorbed in contraction represents structural changes that may involve straininduced orientation, crystallization, improvement in order, closure of longitudinal cracks, or increase in density under stress (designated as structural changes A). Energy absorbed in extension and released in contraction indicates structural changes which may involve opening of cracks under stress, cavitation, volume expansion, etc. (designated as structural changes B).

In most cases, we expect that both types of structural change would occur cooperatively. Since the analysis yields only a net effect, we can only surmise the overriding mechanism in a specific case. That is, a positive value of $\Delta \xi_{\text {ext }}$ indicates that one or a few structural changes B override one or a few structural changes A. A negative value indicates an opposite feature.

The results analyzed for both undrawn and drawn films are summarized in Figure 13. As is clear from the figure, most $\Delta \xi_{\text {ext }}$ 's for undrawn films are negative and those for drawn films are positive, regardless of the crystallization tempetature. But positive maxima are seen at 


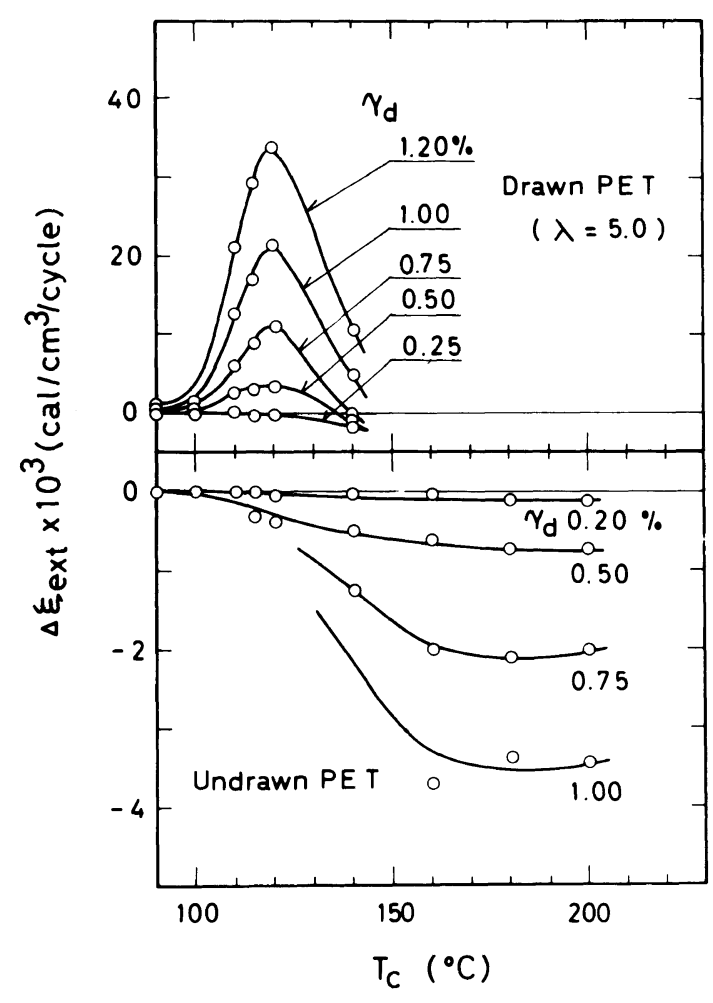

Figure 13. The variation of $\Delta \xi_{\text {ext }}$ with the crystallization temperature $T_{\mathrm{c}}$ at different dynamic strains $\gamma_{\mathrm{d}}$ for the undrawn (bottom) and drawn (top) PET films.

the crystallization temperature of $T_{\mathrm{c}}$ of $120^{\circ} \mathrm{C}$ in the drawn films. The absolute values of $\Delta \xi_{\text {ext }}$ increase with increasing $\gamma_{d}$ for both undrawn and drawn films.

Putting these results together with morphological observation, the following arguments can be made. For undrawn films, the overriding mechanisms are associated with the structural changes such as the strain-induced orientation and improvement in order. However, actual structural changes must be different among the undrawn films crystallized at different temperatures. That is, an overriding mechanism may be considered to be an improvement in order in amorphous regions in the group crystallized at lower temperatures, and strain-induced orientation of amorphous chains in the group crystallized at intermediate temperatures, and strain-induced orientation of crystallites in lamellae in the group crystallized at higher temperatures, as already described above.

The positive maxima observed for drawn films precrystallized around $120^{\circ} \mathrm{C}$ may be interpreted by the manner in which the overriding mechanisms are associated with structural changes such as opening of cracks and cavitation in the amorphous region between spherulites or crystallites. However, in the drawn films precrystallized at other temperatures, the situation seems to be a little different. In the drawn films precrystallized at lower temperatures the structural changes such as slippage of amorphous chains may compensate for positive $\Delta \xi_{\mathrm{ext}}$, while in those precrystallized at higher temperatures the structural changes such as slippage of the crystallites within a spherulitic lamellae may compensate.

Here again, it was suggested that the nonlinear viscoelasticity for drawn films precrystallized at temperatures above $140^{\circ} \mathrm{C}$ may be associated with a different structural change. The structural change might be the slippage of the crystallites within crystalline blocks not being perfectly disrupted, as pointed out in the Lissajous figure of stress and strain.

Thus, the results obtained from ERSISC analysis did not contradict the previous results, but rather supported it. It should be emphasized that the magnitude and sign of $\Delta \xi_{\text {ext }}$ as well as the nonlinear mechanical and optical parameters are very useful parameters in order to investigate what kinds of mechanisms can be attributed to the nonlinear deformation.

All the analyses were carried out at relatively low dynamic strain amplitudes, which are macroscopically in a linear deformation region but microscopically in a nonlinear region. We believe that these results afford an understanding of the macroscopically nonlinear deformation phenomena such as breaking and fatigue of polymer materials. In the future, the relationship between the analytical 
parameters proposed in this article and the macroscopically nonlinear deformation phenomena will be clarified.

\section{APPENDIX 1}

When the following strain is applied to the nonlinear Voigt element (in the element, the elastic constant of spring $G$ is independent of the phase angle of dynamic strain $(\theta=\omega t)$, but the friction constant of dashpot is dependent upon the phase angle, i.e., $\eta(\theta)$ ),

$$
\gamma(\omega t)=\gamma_{s}+\gamma_{d} \sin \omega t
$$

stress can be described as follows:

$$
\sigma(\theta)=\sigma_{\mathrm{s}}+\gamma_{\mathrm{d}}\left(G^{2}+\omega^{2} \eta^{2}(\theta)\right)^{1 / 2} \sin (\theta+\delta(\theta))
$$

where

$$
\begin{aligned}
& \cos (\delta(\theta))=G /\left(G^{2}+\omega^{2} \eta^{2}(\theta)\right)^{1 / 2} \\
& \sin (\delta(\theta))=\omega \eta(\theta) /\left(G^{2}+\omega^{2} \eta^{2}(\theta)\right)^{1 / 2}(\mathrm{~A}-4)
\end{aligned}
$$

Thus,

$$
\begin{aligned}
& \sigma(90)=\sigma_{\mathrm{s}}+G \gamma_{\mathrm{d}} \\
& \sigma(270)=\sigma_{\mathrm{s}}-G \gamma_{\mathrm{d}}
\end{aligned}
$$

Consequently,

$$
G=(\sigma(90)-\sigma(270)) / 2 \gamma_{\mathrm{d}}
$$

\section{REFERENCES}

1. A. Tanaka, M. Fukuda, H. Nagai, M. Shinohara, and S. Onogi, J. Polym. Sci., Polym. Ed., to be published.
2. A. Tanaka, M. Fukuda, and S. Onogi, Rep. Prog. Polym. Phys. Jpn., 21, 269 (1978).

3. A. Tanaka, H. Nagai, and S. Onogi, Rep. Prog. Polym. Phys. Jpn., 22, 451 (1979).

4. A. Tanaka, M. Fukuda, H. Nagai, and S. Onogi, Rep. Prog. Polym. Phys. Jpn., 22, 297 (1979).

5. A. Tanaka, H. Nagai, M. Shinohara, and S. Onogi, Rep. Prog. Polym. Phys. Jpn., 24, 297 (1981).

6. W. H. Cobbs and R. L. Burton, J. Polym. Sci., 10, 275 (1952).

7. A. Keller, J. Polym. Sci., 17, 351 (1955).

8. H. G. Kilian, H. Halboth, and E. Jenckel, Kolloid-Z., 172, 166 (1960).

9. H. G. Zachmann and H. A. Stuart, Macromol. Chem., 41, 131, 148 (1960).

10. A. Keller, "Growth and Perfection of Crystals," D. Turnbull Ed., John Wiley. and Sons, New York, 1958.

11. R. S. Stein, M. B. Rhodes, J. Appl. Phys., 31, 1873 (1960).

12. K. H. Illers and H. Breuer, J. Colloid Sci., 18, 1 (1963).

13. A. B. Thompson and D. W. Woods, Trans. Faraday Soc., 52, 1383 (1956).

14. T. Kawaguchi, J. Polym. Sci., 32, 417 (1958).

15. M. Yoshino and M. Takayanagi, J. Soc. Testing Materials (Japan), 10, (1959).

16. M. Takayanagi, M. Yoshino, and Y. Seki, Zairyoshiken (Japan), 8, 308 (1959).

17. M. Takayanagi, Kobunshi (High Polymers) (Japan), 10, 289 (1961).

18. G. Farrow, J. McIntosh, and I. M. Ward, Macromol. Chem., 38, 147 (1960).

19. J. E. Spruiell, D. E. McCord, and R. A. Beuerlein, Trans. Soc. Rheol., 16, 535 (1972).

20. A. Tanaka, H. Nagano, and S. Onogi, Polym. J., 20, 1003 (1988).

21. D. C. Prevorsek, Y. D. Kwon, and R. K. Sharma, $J$ Macromol. Sci., Phys., B13, 571 (1977).

22. D. C. Prevorsek, Y. D. Kwon, and R. K. Sharma, J. Appl. Polym. Sci., 25, 2063 (1980). 